Review

\title{
Commonly Used Dietary Supplements on Coagulation Function during Surgery
}

\author{
Chong-Zhi Wang *, Jonathan Moss, Chun-Su Yuan \\ Department of Anesthesia \& Critical Care, University of Chicago, Chicago, IL 60637, USA; \\ E-Mails: JM47@dacc.uchicago.edu (J.M.); CYuan@dacc.uchicago.edu (C.-S.Y.) \\ * Author to whom correspondence should be addressed; E-Mail: czwang@uchicago.edu; \\ Tel.: +1-773-702-0166; Fax: +1-773-834-0601.
}

Academic Editor: James D. Adams

Received: 30 May 2015 / Accepted: 22 July 2015 / Published: 27 July 2015

\begin{abstract}
:
Background: Patients who undergo surgery appear to use dietary supplements significantly more frequently than the general population. Because they contain pharmacologically active compounds, dietary supplements may affect coagulation and platelet function during the perioperative period through direct effects, pharmacodynamic interactions, and pharmacokinetic interactions. However, in this regard, limited studies have been conducted that address the pharmacological interactions of dietary supplements. To avoid possible bleeding risks during surgery, information about the potential complications of dietary supplements during perioperative management is important for physicians.
\end{abstract}

Methods: Through a systematic database search of all available years, articles were identified in this review if they included dietary supplements and coagulation/platelet function, while special attention was paid to studies published after 1990.

Results: Safety concerns are reported in commercially available dietary supplements. Effects of the most commonly used natural products on blood coagulation and platelet function are systematically reviewed, including 11 herbal medicines (echinacea, ephedra, garlic, ginger, ginkgo, ginseng, green tea, kava, saw palmetto, St John's wort, and valerian) and four other dietary supplements (coenzyme Q10, glucosamine and chondroitin sulfate, fish oil, and vitamins). Bleeding risks of garlic, ginkgo, ginseng, green tea, saw palmetto, St John's wort, and fish oil are reported. Cardiovascular instability was observed with ephedra, 
ginseng, and kava. Pharmacodynamic and pharmacokinetic interactions between dietary supplements and drugs used in the perioperative period are discussed.

Conclusions: To prevent potential problems associated with the use of dietary supplements, physicians should be familiar with the perioperative effects of commonly used dietary supplements. Since the effects of dietary supplements on coagulation and platelet function are difficult to predict, it is prudent to advise their discontinuation before surgery.

Keywords: dietary supplements; natural products; surgery; coagulation; platelet function; bleeding

\section{Introduction}

Complementary and alternative medicine (CAM) comprises health care practices that are not currently considered an integral part of conventional therapies [1-3]. CAM covers a wide spectrum of ancient to modern approaches that purport to expand options for preventing and treating diseases [4,5]. Some people use CAM to relieve the side effects of conventional treatment or to enhance its effects [6,7]. Others use CAM as a means to increase their sense of control over health care $[8,9]$.

While CAM offers patients more health care options, it is not without risks [10,11]. Not only can CAM result in direct harm, but also the interactions between CAM and conventional medications may delay necessary medical therapies $[12,13]$. Because knowledge of CAM is limited, in many cases, the benefits and risks remain only partially understood. Studies have also confirmed that physicians and other health care professionals have a poor knowledge of CAM [14,15].

Dietary supplements, including herbal medicine derived natural products, are a very commonly used modality in CAM [16,17] and are often used by those who undergo surgical procedures. For example, surgical patients appear to use herbal medicines significantly more frequently than the general population. Tsen et al. reported that $22 \%$ of patients who underwent evaluation in a preoperative clinic took herbs [18]. Kaye et al. found that $32 \%$ of patients in an ambulatory surgery setting admitted to using herbal medications [19]. In a recent retrospective review, $23 \%$ of surgical patients indicated the use of natural products, and older patients preferred dietary supplements [20].

Although the FDA has released Current Good Manufacturing Practices (CGMPs) for Dietary Supplements [21], product variability exists between manufacturers. Because dietary supplements contain pharmacologically active agents, they may affect blood coagulation and platelet function [22-24] through several mechanisms, including direct effects (e.g., intrinsic pharmacologic effects), pharmacodynamic interactions (e.g., alteration of the action of conventional drugs at effector sites), and pharmacokinetic interactions (e.g., alteration of the absorption, distribution, metabolism, elimination, and toxicity of conventional drugs). A relatively small number of studies have successfully addressed the pharmacological interactions of herbal remedies [25,26]. Although limited, a pharmacokinetic analysis of the different constituents in herbal remedies would be useful to clinicians [27,28]. 
Recommendations for the use of dietary supplements are often based on small clinical trials, case reports, animal studies, or predictions derived from known pharmacology and expert opinions. Research is essential because natural products are often widely adopted by the public before adequate data support their safety and efficacy $[29,30]$. A mini review discussed the effects of herbal remedies on the coagulation cascade, however, most information in the article relied on in vitro evidence [31].

In this article, we do not present a comprehensive review of dietary supplements. Rather, we consider specific components relevant to the effects of natural products on hemodynamics, coagulation and platelet function, focusing primarily on the most commonly used herbal medicines and other dietary supplements based on two comprehensive CAM surveys in the United States.

\section{Methods}

\subsection{Database and Search Strategies}

A systematic search was performed in PubMed, SciFinder and Web of Science (1970-2014), with the following terms: (natural product or herbal medicine or dietary supplement or selected natural products) and (coagulation or platelet function or perioperative care). All of those searches ended before December 2014, while special attention was paid to studies published after 1990. In addition, we also performed manual searches in related textbooks and recent surgery and alternative medicine journals. If necessary, further searches were conducted based on information in important references.

\subsection{Fundamental CAM Information from Two Surveys in the U.S.}

To evaluate whether CAM has become an integral part of American health care, the National Institutes of Health conducted two comprehensive surveys in 2002 and 2007. In the 2002 survey, $36.0 \%$ of 31,044 adults interviewed had used some form of CAM in the previous 12 months [32]. In the 2007 survey, $38.3 \%$ of 23,393 adults interviewed had used CAM in the previous year [33]. In the 2007 survey, the most commonly used CAM included natural products (17.7\%), deep breathing exercises $(12.7 \%)$, meditation $(9.4 \%)$, chiropractic or osteopathic manipulation $(8.6 \%)$, massage (8.3\%), and yoga (6.1\%). Between 2002 and 2007, the use of acupuncture, deep breathing exercises, massage therapy, meditation, and yoga increased [33].

\subsection{Selection of Monographs of Natural Products in this Review}

The most commonly used CAM modalities are natural products, e.g., herbal medicines and other dietary supplements [33]. The top ten herbal medicines are echinacea, ginseng, combination herb pills, ginkgo, garlic, green tea, saw palmetto, soy isoflavones, grape seed extract, and milk thistle. The top ten dietary supplements include fish oil or omega 3 or DHA, glucosamine, flaxseed oil, chondroitin, coenzyme Q10, fiber or psyllium, cranberry, melatonin, methylsulfonylmethane (MSM), and lutein [33]. After considering the products that have shown the greatest impact on perioperative patient care, eleven herbal medicines (echinacea, ephedra, garlic, ginger, ginkgo, ginseng, green tea, kava, saw palmetto, St John's wort, and valerian) and four dietary supplements (coenzyme Q10, glucosamine and chondroitin sulfate, fish oil, and vitamins) were selected based on the data from the 2007 Survey and the latest statistical commercial information [34]. 


\section{Results}

\subsection{Preoperative Management for Using of Dietary Supplements}

Although a preoperative assessment should address the patient's use of dietary supplements, a 2005 study showed that $90 \%$ of anesthesiologists do not routinely ask about herbal medicine usage, and $82 \%$ felt their knowledge of herbal medicines and their implications in patient care were inadequate [35]. Moreover, more than $70 \%$ of patients are not forthcoming about their herbal medicine use during routine preoperative assessment [19]. In addition to prescription and over the counter medicines, patients should be asked to bring their herbal medicines and other dietary supplements with them at the time of the preoperative evaluation [36]. A positive history of herbal medicine use should also prompt anesthesiologists to suspect the presence of undiagnosed disorders causing symptoms that lead to self-medication. Patients who use herbal medicines may be more likely than those who do not to avoid conventional diagnosis and therapy [37].

In general, the use of herbal medicines should be discontinued preoperatively. When pharmacokinetic data for the active constituents in an herbal medication are available, the timeframe for preoperative discontinuation can be tailored. For other herbal medicines, two weeks is recommended [38]. However, in clinical practice, because many patients require nonelective surgery, are not evaluated until the day of surgery, or are noncompliant with instructions to discontinue herbal medications preoperatively, they may take herbal medicines until the day of surgery. In this situation, anesthesia can usually proceed safely at the discretion of the anesthesiologist, who should be familiar with commonly used herbal medicines to avoid or recognize and treat complications that may arise $[39,40]$. For instance, recent use of herbal medicines that inhibit platelet function (e.g., garlic, ginseng, or ginkgo) may warrant specific strategies for procedures with substantial intraoperative blood loss (e.g., platelet transfusion) and those that alter the risk-benefit ratio of using certain anesthetic techniques (e.g., neuraxial blockade) [25].

Preoperative discontinuation of all herbal medicines may not eliminate complications associated with their use. Withdrawal of regular medications is associated with increased morbidity and mortality after surgery. In general, medications with the potential to induce rebound and withdrawal symptoms should be continued. The use of noncritical medications that can increase surgical risk should be discontinued. If neither of these conditions apply, consider the patient's risk profile and the risk of the procedure when making perioperative management decisions [41]. In most cases, herbal medicines should be discontinued before surgery because they are not critical. Abstinence after long-term use of an herbal medicine such as valerian has the potential to produce acute withdrawal.

\subsection{Commonly Used Herbal Medicines}

\subsubsection{Echinacea}

Echinacea is a genus of herbaceous flowering plants in the family Asteraceae. Its nine species are commonly called purple coneflowers. Three species, Echinacea angustifolia, Echinacea purpurea, and Echinacea pallida, are used for prophylaxis and treatment of viral, bacterial, and fungal infections, particularly those of upper respiratory origin, although its efficacy in the latter is doubtful [42]. A 2008 
meta-analysis showed echinacea's benefit in decreasing the incidence and duration of the common cold [43]. Pharmacological activity cannot be attributed to a single compound, although the lipophilic fraction, which contains alkylamides, polyacetylenes and essential oils, appears to be more active than the hydrophilic fraction [44].

Echinacea had a number of immunostimulatory effects in early preclinical studies [45]. While there are no studies specifically addressing interactions between echinacea and immunosuppressive drugs, expert opinion generally warns against the concomitant use of echinacea and these drugs, owing to the probability of diminished effectiveness [46]. In contrast to the immunostimulatory effects with short-term use, later observations suggested that long-term use of more than eight weeks has the potential for immunosuppression [46] and a theoretically increased risk of certain complications such as poor wound healing and opportunistic infections. A recent phytochemical study identified a potential immunosuppressant compound cynarin from echinacea [47]. The biological activity of echinacea could be immunostimulatory, immunosuppressive, or anti-inflammatory depending on the portion of the plant and extraction method [48].

Echinacea has also been associated with allergic reactions, including one reported case of anaphylaxis [49]. Therefore, echinacea should be used with caution in patients with asthma, atopy, or allergic rhinitis. Concerns of potential hepatotoxicity have also been raised, although documented cases are lacking [50]. In the absence of definitive information, patients with pre-existing liver dysfunction should be cautioned against using echinacea. Although several in vitro and in vivo pharmacokinetic studies on echinacea have been reported, information about the pharmacokinetics of echinacea is still limited [51]. Echinacea significantly reduced plasma concentrations of S-warfarin, but did not significantly affect warfarin pharmacodynamics and platelet aggregation in healthy subjects [52].

\subsubsection{Ephedra}

Ephedra, known as ma huang in Chinese medicine, comprises the aerial parts of three principal plant species: Ephedra sinica, Ephedra equisetina, and Ephedra intermedia var. tibetica. Ephedra contains alkaloids including ephedrine, pseudoephedrine, norephedrine, methylephedrine, and norpseudoephedrine [53]. In Chinese medicine, it is used to treat respiratory conditions, such as asthma and bronchitis. Ephedra-containing dietary supplements were once widely used in the U.S. to promote weight reduction and enhance energy. In one clinical study, the combination of caffeine and ephedra significantly increased resting energy expenditure, heart rate and blood pressure [54]. Publicity about adverse reactions to this herb prompted the FDA to ban its sale in 2004, but ephedra is still widely available via the Internet.

Ephedra causes dose-dependent increases in blood pressure and heart rate. Ephedrine, the predominant active compound, is a non-catecholamine sympathomimetic that exhibits $\alpha_{1}, \beta_{1}$ and $\beta_{2}$ activity directly at adrenergic receptors and indirectly by releasing endogenous norepinephrine (noradrenaline). These sympathomimetic effects have been associated with more than 800 reported adverse events, including fatal cardiac and central nervous system complications [55].

Ephedra may affect cardiovascular function and vasoconstriction, and, in some cases, vasospasm of coronary and cerebral arteries may cause myocardial infarction and thrombotic stroke [56]. Ephedra also caused hypersensitivity myocarditis, characterized by cardiomyopathy with myocardial 
lymphocyte and eosinophil infiltration [25]. Concomitant use of ephedra and monoamine oxidase inhibitors can result in life-threatening hyperpyrexia, hypertension, and coma [57].

In humans, ephedrine has an elimination half-life of $5.2 \mathrm{~h}$ with $70 \%-80 \%$ of the excreted compound remaining unchanged in the urine [58]. Based upon the pharmacokinetic data and the known cardiovascular risks of ephedra, including myocardial infarction, stroke and cardiovascular collapse from catecholamine depletion [57], this herb should be not used as a dietary supplement.

\subsubsection{Garlic}

Garlic (Allium sativum) has the potential to modify the risk of developing atherosclerosis by reducing blood pressure, thrombus formation, and serum lipid and cholesterol levels [59]. These effects are primarily attributed to the sulfur-containing compounds, particularly allicin and its transformation products. Commercial garlic preparations may be standardized to a fixed alliin and allicin content [60].

Garlic inhibits platelet aggregation in vivo in a dose-dependent fashion [61,62]. The effect of one of its constituents, ajoene, appears to be irreversible and may potentiate the effect of other platelet inhibitors such as prostacyclin, forskolin, indomethacin, and dipyridamole [63]. Although these effects have not been consistently demonstrated in clinical trials [64], there are several cases in the literature on excessive dietary garlic intake or use of garlic as a medicine associated with coagulation alterations [65]. One case report showed an interaction between garlic and warfarin, resulting in an increased INR [66]. In addition to bleeding concerns, garlic has the potential to decrease systemic and pulmonary vascular resistance in laboratory animals, an effect that was observed in clinical studies as well [67].

In an early study in rats, alliin was absorbed quickly after oral administration and eliminated after $6 \mathrm{~h}$. Allicin was absorbed slowly after oral administration, and its plasma peak level appeared between $0.5 \mathrm{~h}$ and $2 \mathrm{~h}$. Even four days later, allicin could still be detected in the rats [68]. Although in one clinical study garlic oil selectively inhibited CYP2E1 activity [69], it is still difficult to predict drug interactions with garlic [70,71].

\subsubsection{Ginger}

Ginger (Zingiber officinale), a popular spice, has a long history of use in Chinese, Indian, Arabic, and Greco-Roman herbal medicines. Ginger has a wide range of reported health benefits for those with arthritis, rheumatism, sprains, muscular aches, pains, sore throats, cramps, constipation, indigestion, nausea, vomiting, hypertension, dementia, fever, infectious diseases, and helminthiasis [72-74]. Ginger contains up to $3 \%$ volatile oil, mostly monoterpenoids and sesquiterpenoids [75]. Gingerols are representative compounds in ginger [76].

Ginger is an anti-emetic and has been used to treat motion sickness and to prevent nausea after laparoscopy [77]. In an in vitro study, gingerols and related analogues inhibited arachidonic acid-induced human platelet serotonin release and aggregation, with a potency similar to that of aspirin [76]. In another in vitro study, the antiplatelet effects of 20 ginger constituents were evaluated. Five constituents showed antiplatelet activities at relatively low concentrations. One of the ginger compounds (8-paradol) was the most potent COX-1 inhibitor and antiplatelet aggregation agent [78]. In a case report, a ginger-phenprocoumon combination resulted in an elevated INR and epistaxis [79]. 
Although the sample size was relatively small, the platelet inhibition potential of ginger has been supported in a pilot clinical study [80].

\subsubsection{Ginkgo}

Ginkgo is derived from the leaf of Ginkgo biloba, the sole surviving species of the large plant division Ginkgophyta, once widespread throughout the world 180 million years ago. Ginkgo extracts used as medicine contain terpene trilactones, flavonoids, biflavones, proanthocyanidins, alkylphenols, and polyprenols $[81,82]$. Ginkgo has been used for cognitive disorders, peripheral vascular disease, age-related macular degeneration, vertigo, tinnitus, erectile dysfunction, and altitude sickness [83-85]. Studies have suggested that ginkgo may stabilize or improve cognitive performance in patients with Alzheimer's disease and multi-infarct dementia [86] but not in healthy geriatric patients [87]. When plasma and brain levels of terpene trilactones were evaluated in vivo, ginkgolides $\mathrm{A}$ and $\mathrm{B}$ and bilobalide crossed the blood-brain barrier after a single oral dose of ginkgo extract [88]. Because the compounds believed to be responsible for its pharmacological effects are the terpene trilactones and flavonoids, most commercial ginkgo extracts are standardized for their content of these compounds [81].

Ginkgo appears to alter vasoregulation, act as an antioxidant, modulate neurotransmitter and receptor activity and inhibit platelet-activating factor (PAF). Of these effects, the inhibition of PAF raises the greatest concern for surgical patients [38]. Ginkgo showed antiplatelet and antithrombotic effects in in vivo animal models [89,90]. In a clinical trial, ginkgo reduced platelet aggregation but had no effect on coagulation assays or bleeding time [91]. In a study of 50 healthy male volunteers, 29 received $2 \times 120 \mathrm{mg} /$ day of ginkgo extract for seven days; however, none in the ginkgo group had abnormal platelet and coagulation parameters [92]. Despite lack of evidence from a clinical trial, ten case reports have implicated ginkgo as a cause of catastrophic bleeding [93,94], including one case of spontaneous hyphema [95], one case of postoperative bleeding after laparoscopic cholecystectomy [96], and one of cerebral bleeding without structural abnormalities in the patient [94].

Terpene trilactones are highly bioavailable when administered orally. The elimination half-lives of the terpene trilactones after oral administration are between $3 \mathrm{~h}$ and $10 \mathrm{~h}$. For ginkgolide $\mathrm{B}$, a dosage of $40 \mathrm{mg}$ twice daily resulted in a higher area under the curve, and a longer half-life and residence time than after a single $80 \mathrm{mg}$ dose. A once daily dose of $80 \mathrm{mg}$ guaranteed a higher maximum concentration peak $\left(\mathrm{T}_{\max }\right)$. $\mathrm{T}_{\max }$ was reached $2-3 \mathrm{~h}$ after administration with both dosages [97].

\subsubsection{Ginseng}

Among the several species of ginseng used for their pharmacological effects, Asian ginseng (Panax ginseng) and American ginseng (Panax quinquefolius) are the most commonly described [17,98]. Ginseng has been labeled an "adaptogen" since it reportedly protects the body against stress and restores homeostasis [99-101]. Because its pharmacological actions are attributed to the ginsenosides, a group of steroidal saponin compounds, many commercially available ginseng preparations have been standardized to ginsenoside content $[17,102]$.

The many heterogeneous and sometimes opposing effects of different ginsenosides [103,104] give ginseng a broad but incompletely understood pharmacological profile with regards to its effects on 
general health, fatigue, immune function, cancer, cardiovascular disease, diabetes mellitus, cognitive function, viral infections, sexual function, and athletic performance [99]. The underlying mechanism appears to be similar to that classically described for steroid hormones. A potential therapeutic use for this herb lies in its ability to lower postprandial blood glucose in both type 2 diabetics and non-diabetics $[105,106]$, an effect that may create unintended hypoglycemia in patients who have fasted before surgery. In a recent case report, after the oral administration a large amount of ginseng, a female patient with no cardiovascular risk factors developed prolonged QT with subsequent Torsades de pointes, suggesting that a high dose of ginseng may have a risk of inducing arrhythmia [107].

There is concern about ginseng's effect on hemostasis. One early study suggested that the antiplatelet activity of panaxynol, a constituent of ginseng, may be irreversible in humans [108]. Other studies found that ginseng extract and ginsenosides inhibit platelet aggregation in vitro $[109,110]$, and prolong both thrombin time and activated partial thromboplastin time in in vivo animal models [111,112]. The clinical evidence implicating ginseng as a cause of bleeding is weak and based on only a few case reports [93]. Although ginseng may inhibit the coagulation cascade, in one case its use was associated with a significant decrease in warfarin anticoagulation [113]. Subsequently, a study involving volunteers showed that American ginseng interfered with warfarin-induced anticoagulation [114]. In another clinical trial, warfarin's apparent clearance was moderately increased with Asian ginseng [115]. Because warfarin is often used after orthopedic or vascular procedures, this drug interaction may affect the outcome of the procedure.

In rats, after an intravenous infusion of ginseng, ginsenosides $\mathrm{Re}$ and $\mathrm{Rg} 1$ were eliminated quickly from the body with a $\mathrm{T}_{1 / 2}$ between $0.7 \mathrm{~h}$ and $4 \mathrm{~h}$; ginsenosides $\mathrm{Rb} 1$ and $\mathrm{Rd}$ were eliminated slowly from the body with a $\mathrm{T}_{1 / 2}$ between $19 \mathrm{~h}$ and $22 \mathrm{~h}$ [116]. After the oral administration of ginseng, ginsenoside $\mathrm{Rb} 1$ reached the maximum plasma concentration at approximately $4 \mathrm{~h}$ with a prolonged half-life [117,118].

\subsubsection{Green Tea}

Tea from Camellia sinensis is one of the most ancient drinks and the second most widely consumed beverage in the world $[119,120]$. Tea can be classified into three types: green, oolong, and black. Green tea, which is non-fermented and derived directly from drying and steaming fresh tea leaves, contains polyphenolic compounds. The catechins in green tea account for $16 \%-30 \%$ of its dry weight. Epigallocatechin-3-gallate (EGCG), the most predominant catechin in green tea, is responsible for much of the biological activity mediated by green tea [120].

In an early in vitro and in vivo study, both green tea and EGCG significantly prolonged mouse tail bleeding time in conscious mice. They inhibited adenosine diphosphate- and collagen-induced rat platelet aggregation in a dose-dependent manner [121]. The antiplatelet activity may result from the inhibition of thromboxane A2 formation. Because ATP release from a dense granule is inhibited by catechins in washed platelets, thromboxane A2 formation may have been inhibited by preventing arachidonic acid liberation and thromboxane A2 synthase [122,123]. Regarding a possible adverse effect of green tea on platelets, one case report showed that after a patient consumed a weight-loss product containing green tea, thrombotic thrombocytopenic purpura developed [124]. Since green tea contains vitamin K, drinking green tea may antagonize the anticoagulant effects of warfarin [125]. 
In a randomized, double-blind, placebo-controlled study, eight subjects received oral EGCG in a single dose of 50-1600 $\mathrm{mg}$. In each dosage group, the kinetic profile revealed rapid absorption with a one-peak plasma concentration versus time course, followed by a multiphasic decrease consisting of a distribution phase and an elimination phase. The mean half-life values observed were between $1.9 \mathrm{~h}$ and $4.6 \mathrm{~h}$ [126]. In another pilot clinical study, after five healthy subjects took tea extract orally, the concentration of EGCG in plasma was determined; the half-life of EGCG was between $2.2 \mathrm{~h}$ and $3.4 \mathrm{~h}[127]$.

\subsubsection{Kava}

Kava is derived from the dried root of the pepper plant Piper methysticum. Kava has gained popularity as an anxiolytic and sedative, and kavalactones appear to be the source of kava's pharmacological activity [53].

Kava possesses psychomotor activities. The kavalactones have dose-dependent effects on the central nervous system including antiepileptic, neuroprotective, and local anesthetic properties $[128,129]$. Kava may act as a sedative or hypnotic by potentiating inhibitory neurotransmission of $\gamma$-aminobutyric acid (GABA) [130]. The kavalactones increased barbiturate sleep time in laboratory animals [131]. This effect may explain the mechanism underlying the report of a coma attributed to an alprazolam-kava interaction [132]. Although kava has abuse potential, whether long-term use can result in addiction, tolerance, and acute withdrawal after abstinence has not been satisfactorily investigated. Continuous kava use may elevate gamma glutamyl transpeptidase (GGT) levels, raising concerns about hepatotoxicity [133]. In addition, the hepatotoxicity of kava may be associated with the inappropriate use of plant products and processes [134]. With continuous use, kava produces "kava dermopathy", characterized by reversible scaly cutaneous eruptions [135].

In an in vitro investigation, a kava compound (+)-kavain suppressed the aggregation of human platelets [136]. A pilot survey of extensive usage of kava showed that kava users were more likely to complain of poor health and had increased red-cell volume and decreased platelet volume [137]. Kava inhibits cyclooxygenase to potentially decrease renal blood flow and interfere with platelet aggregation. Consumption of kava has potential cardiovascular effects that could manifest and the elimination half-life of kavalactones is $9 \mathrm{~h}$ [138]. The kavalactone compound kawain was well absorbed after oral administration during surgery [139]. In spite of safety concerns, including previous reports of liver toxicity associated with kava products in humans [140,141], kava is still available in the United States.

Peak plasma levels occur $1.8 \mathrm{~h}$ after an oral dose, and $>90 \%$ of the dose and its metabolites were eliminated within $72 \mathrm{~h}[142]$.

\subsubsection{Saw Palmetto}

Saw palmetto (Serenoa repens) is a dwarf palm tree native to Florida and other parts of the southeastern USA. The dried ripe berry extract of saw palmetto is used by men in the United States to treat symptoms associated with benign prostatic hypertrophy (BPH) [143]. The major constituents of saw palmetto are fatty acids and their glycerides (i.e., triacylglycerides and monoacylglycerides), 
carbohydrates, steroids, flavonoids, resin, pigment, tannin, and volatile oil. The pharmacological activity of saw palmetto has not been attributed to a single compound [53].

The mechanisms of saw palmetto, including antiandrogenic, anti-inflammatory, and antiproliferative effects mediated through the inhibition of growth factors, have been studied in vitro [144]. An in vivo study revealed that at a clinically relevant dose, saw palmetto exerts a direct effect on the pharmacological receptors in the lower urinary tract, thereby improving urinary dysfunction in patients with BPH and overactive bladders [145]. The potential of saw palmetto for relieving BPH symptoms could be achieved by multiple synergistic mechanisms.

Platelet function was not affected by the administration of saw palmetto in a clinical study [93], and two case reports provided little evidence to implicate saw palmetto as a cause of bleeding. In a patient undergoing a craniotomy, however, saw palmetto was associated with excessive surgical bleeding that required termination of the procedure. This complication was attributed to saw palmetto's anti-inflammatory effects, specifically the inhibition of cyclooxygenase and subsequent platelet dysfunction [146]. Another case of hematuria and coagulopathy in a patient who used saw palmetto was reported [147].

\subsubsection{St John's Wort}

St John's wort is the common name for Hypericum perforatum, primarily used as an antidepressant. The popularity of St John's wort is reflected in the large number of clinical trials, meta-analyses and reviews of its effectiveness as an antidepressant. The herb is more effective than a placebo in the treatment of mild to moderate depression and the incidence of side effects is low. In the treatment of major depression, however, St John's wort is less effective [148]. The compounds believed to be responsible for pharmacological activity are hypericin and hyperforin [149]; thus, commercial preparations are often standardized for the content of the two compounds [150].

St John's wort inhibits serotonin, norepinephrine and dopamine reuptake [151]. Concomitant use of this herb with or without serotonin reuptake inhibitors may create a syndrome of central serotonin excess [152]. Although in vitro data implicated monoamine oxidase inhibition as a possible mechanism of action, a number of later investigations have demonstrated that monoamine oxidase inhibition with St John's wort is insignificant in vivo [153].

The use of St John's wort can significantly increase the metabolism of many other drugs [70,154]. For example, it induces the cytochrome P450 3A4 isoform, approximately doubling its metabolic activity [155,156]. Interactions with substrates of the 3A4 isoform including indinavir sulfate [157], ethinylestradiol [158], and cyclosporine have been documented. In two case reports of heart transplant patients, after taking St John's wort, their plasma cyclosporine concentrations became subtherapeutic and acute transplant rejection was shown. After stopping St John's wort, plasma cyclosporine remained within the therapeutic range with no further episodes of rejection [159]. In one series of 45 organ transplant patients, St John's wort was associated with an average decrease of $49 \%$ of cyclosporine levels in blood [160]. Another group reported two cases of acute heart transplant rejection associated with this particular pharmacokinetic interaction [159]. Other P450 3A4 substrates are alfentanil, midazolam, lidocaine, calcium channel blockers and 5-hydroxytryptamine receptor antagonists. In addition to the 3A4 isoform, the cytochrome P450 2C9 isoform also may be induced. 
The anticoagulant effect of warfarin, a substrate of the 2C9 isoform, was reduced in seven reported cases [158]. Other 2C9 substrates include the non-steroidal anti-inflammatory drugs. Furthermore, enzyme induction by St John's wort may be more pronounced when other herbal enzyme inducers are taken concomitantly. St John's wort also affects digoxin pharmacokinetics [161]. In rats, St John's wort markedly altered hepatocyte intracellular accumulation of irinotecan and its major metabolite (SN-38) and the glucuronidation of SN-38 [162].

Two clinical trials showed that St John's wort increased estrogen metabolism and caused breakthrough menstrual bleeding in users of estrogen-based oral contraceptives [163,164]. In one case report, St John's wort may have caused severe unilateral epistaxis requiring surgical arrest of bleeding via endoscopic sphenopalatine artery ligation and anterior ethmoidal artery ligation [165].

Several clinical evaluations of the single-dose and steady-state pharmacokinetics of hypericin and hyperforin have been conducted in humans [166]. After oral administration, peak plasma levels of hypericin and hyperforin were obtained between $2.5-8.1 \mathrm{~h}$ and $2.5-4.4 \mathrm{~h}$, respectively, and their median elimination half-lives were $6.0-48.2 \mathrm{~h}$ and $8.5-19.6 \mathrm{~h}$, respectively.

\subsubsection{Valerian}

Valerian, which consists of the root of Valeriana officinalis and a number of other Valeriana species, is an herb native to the temperate areas of the Americas, Europe, and Asia [53]. It is used as a sedative, particularly in the treatment of insomnia, and virtually all herbal sleep-aids contain valerian [167]. The compounds in valerian act synergistically, but the sesquiterpenes are the primary source of valerian's pharmacological effects. Commercially available preparations may be standardized to valerenic acid [168].

Valerian produces dose-dependent sedation and hypnosis [169]. These effects appear to be mediated through the modulation of GABA neurotransmission and receptor function [170]. Valerian increased barbiturate sleep time in experimental animals [171]. In several randomized, placebo-controlled trials in humans, there is a mild subjective improvement in sleep with valerian, especially when used for two weeks or more [172,173]. Objective tests have had less consistent results with little or no improvement in sleep noted [174]. In one patient, valerian withdrawal appeared to mimic an acute benzodiazepine withdrawal syndrome characterized by delirium and cardiac complications after surgery. Symptoms were attenuated by benzodiazepine administration [175]. Based upon these findings, valerian is expected to potentiate the sedative effects, like midazolam, via the GABA receptor.

The pharmacokinetics of valerian were evaluated in two clinical studies. In five healthy adults, serum concentration of valerenic acid was at maximum between 1 and $2 \mathrm{~h}$ after administration. Valerenic acid was measurable in serum for at least $5 \mathrm{~h}$ after the valerian dose [176]. In another study, plasma peak levels appeared between $0.47 \mathrm{~h}$ and $1.7 \mathrm{~h}$. The large variability in the pharmacokinetics of valerenic acid may contribute to the inconsistencies in its effect as a sleep aid [177].

Most of the published clinical trials do not record side effects of valerian. In a trial involving 61 patients, there were only three cases of side-effects: two of headache and one of morning hang-over [169]. Another possible rare adverse effect of valerian is hepatotoxicity, found in one case report [178]. Abrupt discontinuation in patients who may be physically dependent on valerian risk benzodiazepine- 
like withdrawal. Based upon the mechanism of action and a reported case of efficacy [175], benzodiazepines can be used to treat valerian withdrawal symptoms.

\subsubsection{Other Herbal Medicines}

In the survey conducted in 2007, the top ten herbal medicines also included soy isoflavones, grape seed extract, and milk thistle. There is no report on adverse effects related to coagulation and platelet function for these herbs. Antiplatelet aggregation activity and herb-drug interactions, however, were found in other herbs including boldo (Peumus boldus), Danshen (Salvia miltiorrhiza), Dong quai (Angelica sinensis) and papaya (Carica papaya) [179].

Danshen is a very commonly used Chinese herbal medicine for cardiovascular conditions [180-182]. In a clinical trial, this herbal medicine has been shown to be effective in reducing skin flap ischemia and necrosis after mastectomy [183]. The effects of antiplatelet aggregation of Danshen have been reported from a number of investigations. An in vitro study demonstrated that the intracellular signaling pathway involved in the antiplatelet action of tanshinone IIA could modulate tubulin acetylation and inhibit Erk-2 phosphorylation [184,185]. Cryptotanshinone is another pharmacologically active compound identified from Danshen. In a very recent study, Maione et al. reported that cryptotanshinone inhibited rat platelet aggregation and endowed of Gi-coupled P2Y12 receptor antagonist [186].

\subsection{Other Commonly Used Dietary Supplements}

\subsubsection{Coenzyme $\mathrm{Q}_{10}$}

Coenzyme $\mathrm{Q}_{10}\left(\mathrm{CoQ}_{10}\right)$, or ubidecarenone, is a single-constituent antioxidant compound structurally related to vitamin $\mathrm{K}$. Endogenous $\mathrm{CoQ}_{10}$ may prevent the membrane transition pore from opening, as it counteracts several apoptotic events, such as DNA fragmentation, cytochrome c release, and membrane potential depolarization [53].

The interaction between CoQ 10 and warfarin was investigated in rats [187]. Following the oral administration of $1.5 \mathrm{mg} / \mathrm{kg}$ of racemic warfarin to rats during an eight-day oral regimen of CoQ 10 $(10 \mathrm{mg} / \mathrm{kg}$ daily), no apparent effect was observed on the serum protein binding of warfarin enantiomers. Treatment with $\mathrm{CoQ}_{10}$ did not affect the absorption and distribution of the $S$ - and $R$-enantiomers of warfarin but increased total serum clearance of both $R$ - and S-warfarin. The increased clearance values could be attributed to the acceleration of certain metabolic pathways and renal excretion of the warfarin enantiomers.

An in vitro study using human liver microsomes led to a relatively accurate pharmacokinetic prediction of CoQ 10 activity. A $32 \%$ and $17 \%$ increase in the total clearance of $S$ - and $R$-warfarin, was predicted with the coadministration of $100 \mathrm{mg} \mathrm{CoQ}_{10}$ [188]. CoQ 10 may decrease the effects of warfarin [189], but results were inconsistent in another controlled, clinical trial [190]. In 171 patients, coadministration of $\mathrm{CoQ}_{10}$ with warfarin appeared to increase the risk of bleeding [191]. Clinical pharmacokinetic study suggested that $\mathrm{CoQ}_{10}$ had a prolonged elimination half-life (38-92 h) after oral administration [192]. 


\subsubsection{Glucosamine and Chondroitin Sulfate}

Osteoarthritis (OA), a chronic illness and the most common of all the joint diseases, affects about $15 \%$ of the world's population and is three times more common in women than in men [193]. Standard therapies can alleviate the symptoms of OA to some extent but cannot prevent disease progression. A number of alternative substances have been touted as beneficial for OA. Although their mode of action may be complex, glucosamine and chondroitin sulfate have been widely accepted as supplements in the management of OA because they are the essential components of proteoglycan in normal cartilage [194]. When a large-scale trial evaluated glucosamine and chondroitin sulfate alone or in combination, pain was not reduced in a group of patients with OA of the knee. Exploratory analyses suggested that the two in combination might be effective in a subgroup of patients with moderate-to-severe knee pain [195].

Long-term clinical data regarding the safety of glucosamine and chondroitin sulfate alone, or in combination, are limited. The use of chondroitin sulfate alone is well tolerated and without any significant adverse drug interaction [194]. One concern regarding the use of glucosamine is its potential to cause or worsen diabetes in animal models [196], an effect supported by clinical studies [197]. In a published report from the FDA MedWatch database, there were 20 reports of glucosamine or glucosamine-chondroitin sulfate use with warfarin. Coagulation was altered as manifested by increased INR or increased bleeding or bruising [198].

When glucosamine is taken orally, $90 \%$ of it is absorbed. Because of extensive first-pass metabolism, only $25 \%$ bioavailability is achieved by oral administration compared with a bioactivity of $96 \%$ with intravenous administration [199]. Peak plasma levels occurred $4 \mathrm{~h}$ after an oral dose and declined to baseline after about $48 \mathrm{~h}$ [200]. Chondroitin sulfate was absorbed slowly after oral ingestion with a plasma peak at $8.7 \mathrm{~h}$ and a decline to baseline at about $24 \mathrm{~h} \mathrm{[201].}$

\subsubsection{Fish Oil}

The intake of fish oil supplements containing omega-3 fatty acids (EPA and DHA) reduces the incidence of many chronic diseases that involve inflammatory processes including cardiovascular diseases, inflammatory bowel disease, cancer, rheumatoid arthritis, and neurodegenerative illnesses [202]. In a recent study, however, omega-3 did not reduce the rate of death in patients with cardiovascular risk factors [203].

Omega-3 fatty acids, however, may inhibit platelet aggregation and increase the risk of bleeding. In vitro experiments have demonstrated an anti-platelet aggregatory effect of omega-3 fatty acids [204], and inhibition correlated with platelet cAMP levels [205]. In vivo studies show that omega-3 fatty acids decreased platelet aggregation but did not influence bleeding time [206,207]. In a clinical study, the inhibition of platelet aggregation by omega-3 fatty acid was gender-specific. EPA was significantly effective in reducing platelet aggregation in males, whereas DHA was not effective compared to the placebo. In females, DHA significantly reduced platelet aggregation but EPA did not [208].

Although evidence for significant bleeding concerns was not found in clinical trials [209,210], several case reports have illustrated a possible interaction between warfarin and omega-3 fatty acids [211]. Extremely elevated INR associated with warfarin in combination with omega-3 fatty acids 
was found in two cases [212,213]. In another case, after a minor fall, a patient developed a subdural hematoma requiring a craniotomy that likely was precipitated by concomitant use of high-dose omega-3 fatty acids with both aspirin and warfarin [214].

\subsubsection{Vitamins}

Vitamins are organic compounds needed for normal metabolic functions. They are traditionally categorized as fat-soluble (vitamins A, D, E, and K) or water-soluble (vitamins B and C and biotin). Only vitamins $\mathrm{C}$ and $\mathrm{E}$ will be discussed here because of their potential effects related to coagulation and platelet function.

Vitamin $\mathrm{C}$ is a micronutrient essential for human health. Because humans cannot synthesize it, human survival depends on obtaining vitamin $\mathrm{C}$ from foods. The recommended dietary allowance (RDA) of vitamin $\mathrm{C}$ is $60 \mathrm{mg}$ daily. The tolerable upper intake level is $2000 \mathrm{mg}$ /day according to the Institute of Medicine [215]. The toxic effects of vitamin $C$ are few and dose-dependent. Doses of vitamin $\mathrm{C}$ greater than $2000 \mathrm{mg} /$ day have been associated with multiple adverse effects. Ingestion of 3 to $5 \mathrm{~g}$ at once may cause diarrhea and bloating [53]. Large doses may also precipitate hemolysis in patients with glucose 6-phosphate dehydrogenase deficiency [216]. One case report suggested that vitamin C might interfere with the action of warfarin [217], but other clinical studies did not support the theory [218,219].

Vitamin E is a potent lipid-soluble antioxidant in human plasma and tissues. It has many forms and biological activities. The most active form is $\alpha$-tocopherol. The Food and Nutrition Board defined the human requirements for vitamin $\mathrm{E}$ as only $\alpha$-tocopherol, specifically those forms with $2 R$ - $\alpha$-tocopherol stereochemistry [220]. The RDA for vitamin E is $15 \mathrm{mg}$ /day (or $22.4 \mathrm{IU}$ ) [53], which can be met by dietary sources. The essential upper limit for safety is $1000 \mathrm{mg} / \mathrm{day}$, but some experts advise avoiding supplementation with doses higher than $400 \mathrm{mg} /$ day [221]. Vitamin E intakes are associated with an increased tendency to bleed and in vitro and in vivo studies showed that vitamin $\mathrm{E}$ inhibits platelet aggregation. A vitamin E quinone metabolite may be responsible for the effects of vitamin E [222], and the reduced platelet adhesiveness of vitamin E probably accompanies incorporation by plasma lipoproteins [223]. Risk of bleeding increased when vitamin E and warfarin were combined in an in vitro study [224]; however, this interaction was not supported by a preliminary clinical study [225]. Moderate doses of vitamin E (400 IU daily) increased the risk of bleeding because of inhibition of platelet aggregation and antagonism of vitamin K-dependent clotting factors [226]. In one clinical study, platelet adhesion decreased significantly in volunteers who took 400 IU of vitamin E plus $325 \mathrm{mg}$ /day aspirin, compared to volunteers who took $325 \mathrm{mg}$ /day of aspirin alone [227]. Data from another trial were unable to reproduce these results [228].

Other top ten dietary supplements include flaxseed oil, fiber or psyllium, cranberry, melatonin, methysulfonylmethane (MSM) and lutein [33]. No special concerns have been published associated with bleeding risk or other platelet function changes from the use of these supplements.

\section{Discussion}

Although there are no official standards or guidelines on the preoperative use of alternative medicine, public and professional educational information advises that natural products be 
discontinued at least 2-3 weeks before surgery [38,229]. However, in practice, evaluating patients 2-3 weeks before elective surgery may not be practical. Moreover, some patients require non-elective surgery or are non-compliant with instructions to discontinue herbal medications preoperatively. These factors and the extensive use of herbal medicines may mean that herbal medications are taken until the time of surgery. Pharmacokinetic data on selected active constituents indicate that some herbal medications are eliminated quickly and may be discontinued close to the time of surgery.

The administration of warfarin in the perioperative period may be complicated by the potential drug-supplement interactions described above. Because the effects of dietary supplements on coagulation and platelet function are not well characterized and their effects are difficult to predict, it is prudent to advise their discontinuation before surgery [230].

Data on the safety of dietary supplements in the perioperative period are limited. Since patients often self-medicate with supplements without disclosure to their health care providers, physicians should ask patients about their present or past use of dietary supplements. A limitation of this review is that currently available data are mostly based on in vivo and limited clinical studies or case reports, whereas controlled clinical trials for natural products on coagulation and platelet function are largely unavailable. Nevertheless, we summarized potential perioperative effects of commonly used natural products. Data in this article can help physicians avoid potential problems associated with the use of natural products during the perioperative period.

\section{Conclusions}

Natural products are gaining popularity in the United States. There is extensive literature on the beneficial and adverse effects of natural products; however, safety data related to their bleeding risks are limited. To understand these potential complications of natural products, clinicians should explicitly elicit and document a history of natural product use by patients. In this article, we reviewed possible effects of natural products on coagulation and platelet function. Pharmacodynamic and pharmacokinetic information of commonly used herbal medicine and dietary supplements, and their interactions with anticoagulant medications were discussed. It is important for physicians and health care professionals to stay informed about commonly used natural products and their potential adverse effects, including those on coagulation and platelet function.

\section{Acknowledgments}

This work was supported in part by NIH/NCCAM grants AT004418, and AT005362.

\section{Author Contributions}

C.Z.W.: conception and design, data acquisition and interpretation of data, drafting and finalizing the manuscript; J.M.: conception and design, data interpretation, and manuscript revision; and C.S.Y.: conception and design, data interpretation, and manuscript revision.

\section{Conflicts of Interest}

The authors declare that they have no competing interests. 


\section{Abbreviations}

CAM: Complementary and Alternative Medicine; OA: Osteoarthritis; EPA: Eicosapentaenoic Acid;

DHA: Docosahexaenoic Acid; RDA: Recommended Dietary Allowance; and MSM: Methysulfonylmethane.

\section{References}

1. Shekelle, P.G.; Morton, S.C.; Suttorp, M.J.; Buscemi, N.; Friesen, C. Challenges in systematic reviews of complementary and alternative medicine topics. Ann. Intern. Med. 2005, 142, 1042-1047.

2. Miller, F.G.; Emanuel, E.J.; Rosenstein, D.L.; Straus, S.E. Ethical issues concerning research in complementary and alternative medicine. JAMA 2004, 291, 599-604.

3. Bega, D.; Gonzalez-Latapi, P.; Zadikoff, C.; Simuni, T. A review of the clinical evidence for complementary and alternative therapies in Parkinson's disease. Curr. Treat. Opt. Neurol. 2014, $16,314$.

4. Grant, S.J.; Yu, S.B.; Kiat, H.; Chang, D. The use of complementary and alternative medicine by people with cardiovascular disease: A systematic review. BMC Public Health 2012, 12, 299.

5. Medagama, A.B.; Bandara, R. The use of complementary and alternative medicines (CAMs) in the treatment of diabetes mellitus: Is continued use safe and effective? Nutr. J. 2014, 13, 102.

6. Fouladbakhsh, J. Complementary and alternative modalities to relieve osteoarthritis symptoms: A review of the evidence on several therapies often used for osteoarthritis management. Orthop. Nurs. 2012, 31, 115-121.

7. Yamaguchi, Y.; Miyahara, E.; Hihara, J. Efficacy and safety of orally administered Lentinula edodes mycelia extract for patients undergoing cancer chemotherapy: A pilot study. Am. J. Chin. Med. 2011, 39, 451-459.

8. Geller, S.E.; Studee, L. Botanical and dietary supplements for mood and anxiety in menopausal women. Menopause 2007, 14, 541-549.

9. Wang, J.; Li, Y.; Ni, C.; Zhang, H.; Li, L.; Wang, Q. Cognition research and constitutional classification in Chinese medicine. Am. J. Chin. Med. 2011, 39, 651-660.

10. Reddy, K.K.; Grossman, L.; Rogers, G.S. Common complementary and alternative therapies with potential use in dermatologic surgery: Risks and benefits. J. Am. Acad. Dermatol. 2011, 68, e127-e135.

11. Chan, P.C.; Peckham, J.C.; Malarkey, D.E.; Kissling, G.E.; Travlos, G.S.; Fu, P.P. Two-year toxicity and carcinogenicity studies of Panax ginseng in Fischer 344 rats and B6C3F1 mice. Am. J. Chin. Med. 2011, 39, 779-788.

12. Efferth, T.; Koch, E. Complex interactions between phytochemicals. The multi-target therapeutic concept of phytotherapy. Curr. Drug Targets 2011, 12, 122-132.

13. Rodriguez, M.; Du, G.J.; Wang, C.Z.; Yuan, C.S. Letter to the editor: Panaxadiol's anticancer activity is enhanced by epicatechin. Am. J. Chin. Med. 2010, 38, 1233-1235.

14. Cohen, M.H.; Eisenberg, D.M. Potential physician malpractice liability associated with complementary and integrative medical therapies. Ann. Intern. Med. 2002, 136, 596-603. 
15. Ashar, B.H.; Rice, T.N.; Sisson, S.D. Physicians' understanding of the regulation of dietary supplements. Arch. Intern. Med. 2007, 167, 966-969.

16. Wang, C.Z.; Mehendale, S.R.; Calway, T.; Yuan, C.S. Botanical flavonoids on coronary heart disease. Am. J. Chin. Med. 2011, 39, 661-671.

17. Qi, L.W.; Wang, C.Z.; Yuan, C.S. Isolation and analysis of ginseng: Advances and challenges. Nat. Prod. Rep. 2011, 28, 467-495.

18. Tsen, L.C.; Segal, S.; Pothier, M.; Bader, A.M. Alternative medicine use in presurgical patients. Anesthesiology 2000, 93, 148-151.

19. Kaye, A.D.; Clarke, R.C.; Sabar, R.; Vig, S.; Dhawan, K.P.; Hofbauer, R.; Kaye, A.M. Herbal medicines: Current trends in anesthesiology practice-A hospital survey. J. Clin. Anesth. 2000, $12,468-471$.

20. King, A.R.; Russett, F.S.; Generali, J.A.; Grauer, D.W. Evaluation and implications of natural product use in preoperative patients: A retrospective review. BMC Complement. Altern. Med. 2009, 9, 38 .

21. Childress, L.; Gay, A.; Zargar, A.; Ito, M.K. Review of red yeast rice content and current Food and Drug Administration oversight. J. Clin. Lipidol. 2013, 7, 117-122.

22. Bhalerao, S.; Deshpande, T.; Thatte, U. Prakriti (Ayurvedic concept of constitution) and variations in platelet aggregation. BMC Complement. Altern. Med. 2012, 12, 248.

23. Lee, J.J.; Kim, T.; Cho, W.K.; Ma, J.Y. Antithrombotic and antiplatelet activities of Soshiho-tang extract. BMC Complement. Altern. Med. 2013, 13, 137.

24. Choi, J.H.; Kim, D.W.; Park, S.E.; Choi, B.S.; Sapkota, K.; Kim, S.; Kim, S.J. Novel thrombolytic protease from edible and medicinal plant Aster yomena (Kitam.) Honda with anticoagulant activity: Purification and partial characterization. J. Biosci. Bioeng. 2014, 118, 372-377.

25. Ang-Lee, M.K.; Moss, J.; Yuan, C.S. Herbal medicines and perioperative care. JAMA 2001, 286, $208-216$.

26. Wang, C.Z.; Calway, T.; Yuan, C.S. Herbal medicines as adjuvants for cancer therapeutics. Am. J. Chin. Med. 2012, 40, 657-669.

27. Butterweck, V.; Derendorf, H. Potential of pharmacokinetic profiling for detecting herbal interactions with drugs. Clin. Pharmacokinet. 2008, 47, 383-397.

28. Wang, Y.; Xie, H.; Pan, S.L. Pharmacokinetics of laetispicine and its brain distribution in rats. Am. J. Chin. Med. 2010, 38, 895-907.

29. Shaw, D. Toxicological risks of Chinese herbs. Planta Med. 2010, 76, 2012-2018.

30. Dog, T.L.; Marles, R.; Mahady, G.; Gardiner, P.; Ko, R.; Barnes, J.; Chavez, M.L.; Griffiths, J.; Giancaspro, G.; Sarma, N.D. Assessing safety of herbal products for menopausal complaints: An international perspective. Maturitas 2010, 66, 355-362.

31. Cordier, W.; Steenkamp, V. Herbal remedies affecting coagulation: A review. Pharm. Biol. 2012, 50, 443-452.

32. Barnes, P.M.; Powell-Griner, E.; McFann, K.; Nahin, R.L. Complementary and alternative medicine use among adults: United States, 2002. Adv. Data 2004, 343, 1-19.

33. Barnes, P.M.; Bloom, B.; Nahin, R.L. Complementary and alternative medicine use among adults and children: United States, 2007. Natl. Health Stat. Rep. 2008, 12, 1-23. 
34. Blumenthal, M.; Lindstrom, A.; Lynch, M.E.; Rea, P. Herb sales continue growth-Up 3.3\% in 2010. HerbalGram 2010, 90, 64-67.

35. McKenzie, A.G.; Simpson, K.R. Current management of patients taking herbal medicines: A survey of anaesthetic practice in the UK. Eur. J. Anaesthesiol. 2005, 22, 597-602.

36. Skinner, C.M.; Rangasami, J. Preoperative use of herbal medicines: A patient survey. $B r$. $J$. Anaesth. 2002, 89, 792-795.

37. Cirigliano, M.; Sun, A. Advising patients about herbal therapies. JAMA 1998, 280, 1565-1566.

38. Rowe, D.J.; Baker, A.C. Perioperative risks and benefits of herbal supplements in aesthetic surgery. Aesthet. Surg. J. 2009, 29, 150-157.

39. Stohs, S.J.; Dudrick, S.J. Nutritional supplements in the surgical patient. Surg. Clin. North Am. 2011, 91, 933-944.

40. Moss, J.; Yuan, C.S. Herbal medicines and perioperative care. Anesthesiology 2006, 105, 441-442.

41. Whinney, C. Perioperative medication management: General principles and practical applications. Cleve. Clin. J. Med. 2009, 76 (Suppl. 4), S126-S132.

42. Turner, R.B.; Bauer, R.; Woelkart, K.; Hulsey, T.C.; Gangemi, J.D. An evaluation of Echinacea angustifolia in experimental rhinovirus infections. N. Engl. J. Med. 2005, 353, 341-348.

43. Shah, S.A.; Sander, S.; White, C.M.; Rinaldi, M.; Coleman, C.I. Evaluation of echinacea for the prevention and treatment of the common cold: A meta-analysis. Lancet Infect. Dis. 2007, 7 , 473-480.

44. Barnes, J.; Anderson, L.A.; Gibbons, S.; Phillipson, J.D. Echinacea species (Echinacea angustifolia (DC.) Hell., Echinacea pallida (Nutt.) Nutt., Echinacea purpurea (L.) Moench): A review of their chemistry, pharmacology and clinical properties. J. Pharm. Pharmacol. 2005, 57, 929-954.

45. Lee, A.N.; Werth, V.P. Activation of autoimmunity following use of immunostimulatory herbal supplements. Arch. Dermatol. 2004, 140, 723-727.

46. Boullata, J.I.; Nace, A.M. Safety issues with herbal medicine. Pharmacotherapy 2000, 20, 257-269.

47. Dong, G.C.; Chuang, P.H.; Chang, K.C.; Jan, P.S.; Hwang, P.I.; Wu, H.B.; Yi, M.; Zhou, H.X.; Chen, H.M. Blocking effect of an immuno-suppressive agent, cynarin, on CD28 of T-cell receptor. Pharm. Res. 2009, 26, 375-381.

48. Benson, J.M.; Pokorny, A.J.; Rhule, A.; Wenner, C.A.; Kandhi, V.; Cech, N.B.; Shepherd, D.M. Echinacea purpurea extracts modulate murine dendritic cell fate and function. Food Chem. Toxicol. 2010, 48, 1170-1177.

49. Mullins, R.J. Echinacea-associated anaphylaxis. Med. J. Aust. 1998, 168, 170-171.

50. Huntley, A.L.; Thompson Coon, J.; Ernst, E. The safety of herbal medicinal products derived from Echinacea species: A systematic review. Drug Saf. 2005, 28, 387-400.

51. Toselli, F.; Matthias, A.; Gillam, E.M. Echinacea metabolism and drug interactions: The case for standardization of a complementary medicine. Life Sci. 2009, 85, 97-106.

52. Abdul, M.I.; Jiang, X.; Williams, K.M.; Day, R.O.; Roufogalis, B.D.; Liauw, W.S.; Xu, H.; Matthias, A.; Lehmann, R.P.; McLachlan, A.J. Pharmacokinetic and pharmacodynamic interactions of echinacea and policosanol with warfarin in healthy subjects. Br. J. Clin. Pharmacol. 2010, 69, 508-515. 
53. Coates, P.M.; Betz, J.M.; Blackman, M.R.; Cragg, G.M.; Levine, M.; Moss, J.; White, J.D., Encyclopedia of Dietary Supplements, 2nd ed.; Informa Healthcare: London, UK, 2010.

54. Vukovich, M.D.; Schoorman, R.; Heilman, C.; Jacob, P., 3rd; Benowitz, N.L. Caffeine-herbal ephedra combination increases resting energy expenditure, heart rate and blood pressure. Clin. Exp. Pharmacol. Physiol. 2005, 32, 47-53.

55. Nightingale, S.L. From the Food and Drug Administration. JAMA 1997, $278,15$.

56. Haller, C.A.; Benowitz, N.L. Adverse cardiovascular and central nervous system events associated with dietary supplements containing ephedra alkaloids. N. Engl. J. Med. 2000, 343, 1833-1838.

57. Soni, M.G.; Carabin, I.G.; Griffiths, J.C.; Burdock, G.A. Safety of ephedra: Lessons learned. Toxicol. Lett. 2004, 150, 97-110.

58. Gurley, B.J.; Gardner, S.F.; White, L.M.; Wang, P.L. Ephedrine pharmacokinetics after the ingestion of nutritional supplements containing Ephedra sinica (ma huang). Ther. Drug Monit. 1998, 20, 439-445.

59. Stevinson, C.; Pittler, M.H.; Ernst, E. Garlic for treating hypercholesterolemia. A meta-analysis of randomized clinical trials. Ann. Intern. Med. 2000, 133, 420-429.

60. Rybak, M.E.; Calvey, E.M.; Harnly, J.M. Quantitative determination of allicin in garlic: Supercritical fluid extraction and standard addition of alliin. J. Agric. Food Chem. 2004, 52, $682-687$.

61. Chan, K.C.; Yin, M.C.; Chao, W.J. Effect of diallyl trisulfide-rich garlic oil on blood coagulation and plasma activity of anticoagulation factors in rats. Food Chem. Toxicol. 2007, 45, 502-507.

62. Fukao, H.; Yoshida, H.; Tazawa, Y.; Hada, T. Antithrombotic effects of odorless garlic powder both in vitro and in vivo. Biosci. Biotechnol. Biochem. 2007, 71, 84-90.

63. Rahman, K. Effects of garlic on platelet biochemistry and physiology. Mol. Nutr. Food Res. 2007, $51,1335-1344$.

64. Scharbert, G.; Kalb Madeleine, L.; Duris, M.; Marschalek, C.; Kozek-Langenecker Sibylle, A. Garlic at dietary doses does not impair platelet function. Anesth. Analg. 2007, 105, 1214-1218, table of contents.

65. Borrelli, F.; Capasso, R.; Izzo, A.A. Garlic (Allium sativum L.): Adverse effects and drug interactions in humans. Mol. Nutr. Food Res. 2007, 51, 1386-1397.

66. Sunter, W.H. Warfarin and garlic. Pharm. J. 1991, 246, 722.

67. Reinhart, K.M.; Coleman, C.I.; Teevan, C.; Vachhani, P.; White, C.M. Effects of garlic on blood pressure in patients with and without systolic hypertension: A meta-analysis. Ann. Pharmacother. 2008, 42, 1766-1771.

68. Lachmann, G.; Lorenz, D.; Radeck, W.; Steiper, M. The pharmacokinetics of the S35 labeled labeled garlic constituents alliin, allicin and vinyldithiine. Arzneim. Forsch. 1994, 44, 734-743.

69. Gurley, B.J.; Gardner, S.F.; Hubbard, M.A.; Williams, D.K.; Gentry, W.B.; Cui, Y.; Ang, C.Y. Cytochrome $\mathrm{P} 450$ phenotypic ratios for predicting herb-drug interactions in humans. Clin. Pharmacol. Ther. 2002, 72, 276-287.

70. Shi, S.; Klotz, U. Drug interactions with herbal medicines. Clin. Pharmacokinet. 2012, 51, $77-104$. 
71. Berginc, K.; Kristl, A. The effect of garlic supplements and phytochemicals on the ADMET properties of drugs. Expert Opin. Drug Metab. Toxicol. 2012, 8, 295-310.

72. Huang, C.F.; Yang, R.S.; Liu, S.H.; Hsieh, P.C.; Lin-Shiau, S.Y. Evidence for improved neuropharmacological efficacy and decreased neurotoxicity in mice with traditional processing of Rhizoma Arisaematis. Am. J. Chin. Med. 2011, 39, 981-998.

73. Al-Suhaimi, E.A.; Al-Riziza, N.A.; Al-Essa, R.A. Physiological and therapeutical roles of ginger and turmeric on endocrine functions. Am. J. Chin. Med. 2011, 39, 215-231.

74. Saenghong, N.; Wattanathorn, J.; Muchimapura, S.; Tongun, T.; Piyavhatkul, N.; Banchonglikitkul, C.; Kajsongkram, T. Zingiber officinale Improves Cognitive Function of the Middle-Aged Healthy Women. Evid. Based Complement. Alternat. Med. 2012, 2012, 383062.

75. Ali, B.H.; Blunden, G.; Tanira, M.O.; Nemmar, A. Some phytochemical, pharmacological and toxicological properties of ginger (Zingiber officinale Roscoe): A review of recent research. Food Chem. Toxicol. 2008, 46, 409-420.

76. Koo, K.L.; Ammit, A.J.; Tran, V.H.; Duke, C.C.; Roufogalis, B.D. Gingerols and related analogues inhibit arachidonic acid-induced human platelet serotonin release and aggregation. Thromb. Res. 2001, 103, 387-397.

77. Pongrojpaw, D.; Chiamchanya, C. The efficacy of ginger in prevention of post-operative nausea and vomiting after outpatient gynecological laparoscopy. J. Med. Assoc. Thai. 2003, 86, 244-250.

78. Nurtjahja-Tjendraputra, E.; Ammit, A.J.; Roufogalis, B.D.; Tran, V.H.; Duke, C.C. Effective anti-platelet and COX-1 enzyme inhibitors from pungent constituents of ginger. Thromb. Res. 2003, 111, 259-265.

79. Kruth, P.; Brosi, E.; Fux, R.; Morike, K.; Gleiter, C.H. Ginger-associated overanticoagulation by phenprocoumon. Ann. Pharmacother. 2004, 38, 257-260.

80. Young, H.Y.; Liao, J.C.; Chang, Y.S.; Luo, Y.L.; Lu, M.C.; Peng, W.H. Synergistic effect of ginger and nifedipine on human platelet aggregation: A study in hypertensive patients and normal volunteers. Am. J. Chin. Med. 2006, 34, 545-551.

81. van Beek, T.A.; Montoro, P. Chemical analysis and quality control of Ginkgo biloba leaves, extracts, and phytopharmaceuticals. J. Chromatogr. A 2009, 1216, 2002-2032.

82. Koh, P.O. Identification of proteins differentially expressed in cerebral cortexes of Ginkgo biloba extract (EGb761)-treated rats in a middle cerebral artery occlusion model-A proteomics approach. Am. J. Chin. Med. 2011, 39, 315-324.

83. Koh, P.O. Gingko biloba extract (EGb 761) attenuates the focal cerebral ischemic injury-induced decrease in astrocytic phosphoprotein PEA-15 levels. Am. J. Chin. Med. 2011, 39, 971-979.

84. Koh, P.O. Gingko biloba extract (EGb 761) prevents cerebral ischemia-induced p70S6 kinase and S6 phosphorylation. Am. J. Chin. Med. 2010, 38, 727-734.

85. Fransen, H.P.; Pelgrom, S.M.; Stewart-Knox, B.; de Kaste, D.; Verhagen, H. Assessment of health claims, content, and safety of herbal supplements containing Ginkgo biloba. Food Nutr. Res. 2010, 54, doi:10.3402/fnr.v54i0.5221.

86. Le Bars, P.L.; Katz, M.M.; Berman, N.; Itil, T.M.; Freedman, A.M.; Schatzberg, A.F. A placebo-controlled, double-blind, randomized trial of an extract of Ginkgo biloba for dementia. North American EGb Study Group. JAMA 1997, 278, 1327-1332. 
87. Solomon, P.R.; Adams, F.; Silver, A.; Zimmer, J.; deVeaux, R. Ginkgo for memory enhancement: A randomized controlled trial. JAMA 2002, 288, 835-840.

88. Ude, C.; Paulke, A.; Noldner, M.; Schubert-Zsilavecz, M.; Wurglics, M. Plasma and brain levels of terpene trilactones in rats after an oral single dose of standardized Ginkgo biloba extract EGb 761(R). Planta Med. 2011, 77, 259-264.

89. Kim, Y.S.; Pyo, M.K.; Park, K.M.; Park, P.H.; Hahn, B.S.; Wu, S.J.; Yun-Choi, H.S. Antiplatelet and antithrombotic effects of a combination of ticlopidine and ginkgo biloba ext (EGb 761). Thromb. Res. 1998, 91, 33-38.

90. Sasaki, Y.; Noguchi, T.; Yamamoto, E.; Giddings, J.C.; Ikeda, K.; Yamori, Y.; Yamamoto, J. Effects of Ginkgo biloba extract (EGb 761) on cerebral thrombosis and blood pressure in stroke-prone spontaneously hypertensive rats. Clin. Exp. Pharmacol. Physiol. 2002, 29, 963-967.

91. Guinot, P.; Caffrey, E.; Lambe, R.; Darragh, A. Tanakan inhibits platelet-activating-factorinduced platelet aggregation in healthy male volunteers. Haemostasis 1989, 19, 219-223.

92. Kohler, S.; Funk, P.; Kieser, M. Influence of a 7-day treatment with Ginkgo biloba special extract EGb 761 on bleeding time and coagulation: A randomized, placebo-controlled, doubleblind study in healthy volunteers. Blood Coagul. Fibrinolysis 2004, 15, 303-309.

93. Beckert, B.W.; Concannon, M.J.; Henry, S.L.; Smith, D.S.; Puckett, C.L. The effect of herbal medicines on platelet function: An in vivo experiment and review of the literature. Plast. Reconstr. Surg. 2007, 120, 2044-2050.

94. Pedroso, J.L.; Henriques Aquino, C.C.; Escorcio Bezerra, M.L.; Baiense, R.F.; Suarez, M.M.; Dutra, L.A.; Braga-Neto, P.; Povoas Barsottini, O.G. Ginkgo biloba and cerebral bleeding: A case report and critical review. Neurologist 2011, 17, 89-90.

95. Rosenblatt, M.; Mindel, J. Spontaneous hyphema associated with ingestion of Ginkgo biloba extract. N. Engl. J. Med. 1997, 336, 1108.

96. Fessenden, J.M.; Wittenborn, W.; Clarke, L. Gingko biloba: A case report of herbal medicine and bleeding postoperatively from a laparoscopic cholecystectomy. Am. Surg. 2001, 67, 33-35.

97. Drago, F.; Floriddia, M.L.; Cro, M.; Giuffrida, S. Pharmacokinetics and bioavailability of a Ginkgo biloba extract. J. Ocul. Pharmacol. Ther. 2002, 18, 197-202.

98. Nagappan, A.; Karunanithi, N.; Sentrayaperumal, S.; Park, K.I.; Park, H.S.; Lee do, H.; Kang, S.R.; Kim, J.A.; Senthil, K.; Natesan, S.; et al. Comparative root protein profiles of Korean ginseng (Panax ginseng) and Indian ginseng (Withania somnifera). Am. J. Chin. Med. 2012, 40, 203-218.

99. Attele, A.S.; Wu, J.A.; Yuan, C.S. Ginseng pharmacology: Multiple constituents and multiple actions. Biochem. Pharmacol. 1999, 58, 1685-1693.

100. Hwang, J.W.; Oh, J.H.; Yoo, H.S.; Lee, Y.W.; Cho, C.K.; Kwon, K.R.; Yoon, J.H.; Park, J.; Her, S.; Lee, Z.W.; et al. Mountain ginseng extract exhibits anti-lung cancer activity by inhibiting the nuclear translocation of NF-kappaB. Am. J. Chin. Med. 2012, 40, 187-202.

101. Shergis, J.L.; Zhang, A.L.; Zhou, W.; Xue, C.C. Quality and risk of bias in Panax ginseng randomized controlled trials: A review. Am. J. Chin. Med. 2013, 41, 231-252.

102. Zhang, H.M.; Li, S.L.; Zhang, H.; Wang, Y.; Zhao, Z.L.; Chen, S.L.; Xu, H.X. Holistic quality evaluation of commercial white and red ginseng using a UPLC-QTOF-MS/MS-based metabolomics approach. J. Pharm. Biomed. Anal. 2012, 62, 258-273. 
103. Sievenpiper, J.L.; Arnason, J.T.; Leiter, L.A.; Vuksan, V. Null and opposing effects of Asian ginseng (Panax ginseng C.A. Meyer) on acute glycemia: Results of two acute dose escalation studies. J. Am. Coll. Nutr. 2003, 22, 524-532.

104. Sengupta, S.; Toh, S.A.; Sellers, L.A.; Skepper, J.N.; Koolwijk, P.; Leung, H.W.; Yeung, H.W.; Wong, R.N.; Sasisekharan, R.; Fan, T.P. Modulating angiogenesis: The yin and the yang in ginseng. Circulation 2004, 110, 1219-1225.

105. Attele, A.S.; Zhou, Y.P.; Xie, J.T.; Wu, J.A.; Zhang, L.; Dey, L.; Pugh, W.; Rue, P.A.; Polonsky, K.S.; Yuan, C.S. Antidiabetic effects of Panax ginseng berry extract and the identification of an effective component. Diabetes 2002, 51, 1851-1858.

106. Xie, J.T.; Wang, C.Z.; Ni, M.; Wu, J.A.; Mehendale, S.R.; Aung, H.H.; Foo, A.; Yuan, C.S. American ginseng berry juice intake reduces blood glucose and body weight in ob/ob mice. J. Food Sci. 2007, 72, S590-S594.

107. Torbey, E.; Abi Rafeh, N.; Khoueiry, G.; Kowalski, M.; Bekheit, S. Ginseng: A potential cause of long QT. J. Electrocardiol. 2011, 44, 357-358.

108. Teng, C.M.; Kuo, S.C.; Ko, F.N.; Lee, J.C.; Lee, L.G.; Chen, S.C.; Huang, T.F. Antiplatelet actions of panaxynol and ginsenosides isolated from ginseng. Biochim. Biophys. Acta 1989, 990, $315-320$.

109. Lee, W.M.; Kim, S.D.; Park, M.H.; Cho, J.Y.; Park, H.J.; Seo, G.S.; Rhee, M.H. Inhibitory mechanisms of dihydroginsenoside $\mathrm{Rg} 3$ in platelet aggregation: Critical roles of ERK2 and cAMP. J. Pharm. Pharmacol. 2008, 60, 1531-1536.

110. Lee, J.G.; Lee, Y.Y.; Kim, S.Y.; Pyo, J.S.; Yun-Choi, H.S.; Park, J.H. Platelet antiaggregating activity of ginsenosides isolated from processed ginseng. Pharmazie 2009, 64, 602-604.

111. Jin, Y.R.; Yu, J.Y.; Lee, J.J.; You, S.H.; Chung, J.H.; Noh, J.Y.; Im, J.H.; Han, X.H.; Kim, T.J.; Shin, K.S.; et al. Antithrombotic and antiplatelet activities of Korean red ginseng extract. Basic Clin. Pharmacol. Toxicol. 2007, 100, 170-175.

112. Endale, M.; Lee, W.; Kamruzzaman, S.; Kim, S.; Park, J.; Park, M.; Park, T.; Park, H.; Cho, J.; Rhee, M. Ginsenoside-Rp1 inhibits platelet activation and thrombus formation via impaired GPVI signaling pathway tyrosine phosphorylation and MAPK activation. Br. J. Pharmacol. 2012, 167, 109-127.

113. Janetzky, K.; Morreale, A.P. Probable interaction between warfarin and ginseng. Am. J. Health. Syst. Pharm. 1997, 54, 692-693.

114. Yuan, C.S.; Wei, G.; Dey, L.; Karrison, T.; Nahlik, L.; Maleckar, S.; Kasza, K.; Ang-Lee, M.; Moss, J. Brief communication: American ginseng reduces warfarin's effect in healthy patients: A randomized, controlled Trial. Ann. Intern. Med. 2004, 141, 23-27.

115. Jiang, X.; Blair, E.Y.; McLachlan, A.J. Investigation of the effects of herbal medicines on warfarin response in healthy subjects: A population pharmacokinetic-pharmacodynamic modeling approach. J. Clin. Pharmacol. 2006, 46, 1370-1378.

116. Li, X.; Sun, J.; Wang, G.; Hao, H.; Liang, Y.; Zheng, Y.; Yan, B.; Sheng, L. Simultaneous determination of panax notoginsenoside $\mathrm{R} 1$, ginsenoside $\mathrm{Rg} 1, \mathrm{Rd}, \mathrm{Re}$ and $\mathrm{Rb} 1$ in rat plasma by HPLC/ESI/MS: Platform for the pharmacokinetic evaluation of total panax notoginsenoside, a typical kind of multiple constituent traditional Chinese medicine. Biomed. Chromatogr. 2007, 21, $735-746$. 
117. Munekage, M.; Kitagawa, H.; Ichikawa, K.; Watanabe, J.; Aoki, K.; Kono, T.; Hanazaki, K. Pharmacokinetics of daikenchuto, a traditional Japanese medicine (kampo) after single oral administration to healthy Japanese volunteers. Drug Metab. Dispos. 2011, 39, 1784-1788.

118. Wang, C.Z.; Kim, K.E.; Du, G.J.; Qi, L.W.; Wen, X.D.; Li, P.; Bauer, B.A.; Bissonnette, M.B.; Musch, M.W.; Chang, E.B.; et al. Ultra-performance liquid chromatography and time-of-flight mass spectrometry analysis of ginsenoside metabolites in human plasma. Am. J. Chin. Med. 2011, 39, 1161-1171.

119. Stote, K.S.; Baer, D.J. Tea consumption may improve biomarkers of insulin sensitivity and risk factors for diabetes. J. Nutr. 2008, 138, 1584S-1588S.

120. Wang, C.Z.; Mehendale, S.R.; Yuan, C.S. Commonly used antioxidant botanicals: Active constituents and their potential role in cardiovascular illness. Am. J. Chin. Med. 2007, 35, 543-558.

121. Kang, W.S.; Lim, I.H.; Yuk, D.Y.; Chung, K.H.; Park, J.B.; Yoo, H.S.; Yun, Y.P. Antithrombotic activities of green tea catechins and (-)-epigallocatechin gallate. Thromb. Res. 1999, 96, 229-237.

122. Son, D.J.; Cho, M.R.; Jin, Y.R.; Kim, S.Y.; Park, Y.H.; Lee, S.H.; Akiba, S.; Sato, T.; Yun, Y.P. Antiplatelet effect of green tea catechins: A possible mechanism through arachidonic acid pathway. Prostaglandins Leukot. Essent. Fatty Acids 2004, 71, 25-31.

123. Jin, Y.R.; Im, J.H.; Park, E.S.; Cho, M.R.; Han, X.H.; Lee, J.J.; Lim, Y.; Kim, T.J.; Yun, Y.P. Antiplatelet activity of epigallocatechin gallate is mediated by the inhibition of PLCgamma2 phosphorylation, elevation of PGD2 production, and maintaining calcium-ATPase activity. J. Cardiovasc. Pharmacol. 2008, 51, 45-54.

124. Liatsos, G.D.; Moulakakis, A.; Ketikoglou, I.; Klonari, S. Possible green tea-induced thrombotic thrombocytopenic purpura. Am. J. Health Syst. Pharm. 2010, 67, 531-534.

125. Taylor, J.R.; Wilt, V.M. Probable antagonism of warfarin by green tea. Ann. Pharmacother. 1999, $33,426-428$.

126. Ullmann, U.; Haller, J.; Decourt, J.P.; Girault, N.; Girault, J.; Richard-Caudron, A.S.; Pineau, B.; Weber, P. A single ascending dose study of epigallocatechin gallate in healthy volunteers. J. Int. Med. Res. 2003, 31, 88-101.

127. Gawande, S.; Kale, A.; Kotwal, S. Effect of nutrient mixture and black grapes on the pharmacokinetics of orally administered (-)epigallocatechin-3-gallate from green tea extract: A human study. Phytother. Res. 2008, 22, 802-808.

128. Singh, Y.N.; Singh, N.N. Therapeutic potential of kava in the treatment of anxiety disorders. CNS Drugs 2002, 16, 731-743.

129. Johnson, T.E.; Hermanson, D.; Wang, L.; Kassie, F.; Upadhyaya, P.; O’Sullivan, M.G.; Hecht, S.S.; Lu, J.; Xing, C. Lung tumorigenesis suppressing effects of a commercial kava extract and its selected compounds in A/J mice. Am. J. Chin. Med. 2011, 39, 727-742.

130. Yuan, C.S.; Dey, L.; Wang, A.; Mehendale, S.; Xie, J.T.; Aung, H.H.; Ang-Lee, M.K. Kavalactones and dihydrokavain modulate GABAergic activity in a rat gastric-brainstem preparation. Planta Med. 2002, 68, 1092-1096. 
131. Jamieson, D.D.; Duffield, P.H.; Cheng, D.; Duffield, A.M. Comparison of the central nervous system activity of the aqueous and lipid extract of kava (Piper methysticum). Arch. Int. Pharmacodyn. Ther. 1989, 301, 66-80.

132. Almeida, J.C.; Grimsley, E.W. Coma from the health food store: Interaction between kava and alprazolam. Ann. Intern. Med. 1996, 125, 940-941.

133. Brown, A.C.; Onopa, J.; Holck, P.; Kaufusi, P.; Kabasawa, D.; Craig, W.J.; Dragull, K.; Levine, A.M.; Baker, J.D. Traditional kava beverage consumption and liver function tests in a predominantly Tongan population in Hawaii. Clin. Toxicol. (Phila) 2007, 45, 549-556.

134. Teschke, R.; Schulze, J. Risk of kava hepatotoxicity and the FDA consumer advisory. JAMA 2010, 304, 2174-2175.

135. Gounder, R. Kava consumption and its health effects. Pac. Health Dialog. 2006, 13, 131-135.

136. Gleitz, J.; Beile, A.; Wilkens, P.; Ameri, A.; Peters, T. Antithrombotic action of the kava pyrone (+)-kavain prepared from Piper methysticum on human platelets. Planta Med. 1997, 63, 27-30.

137. Mathews, J.D.; Riley, M.D.; Fejo, L.; Munoz, E.; Milns, N.R.; Gardner, I.D.; Powers, J.R.; Ganygulpa, E.; Gununuwawuy, B.J. Effects of the heavy usage of kava on physical health: Summary of a pilot survey in an aboriginal community. Med. J. Aust. 1988, 148, 548-555.

138. Pepping, J. Kava: Piper methysticum. Am. J. Health. Syst. Pharm. 1999, 56, 957-958, 960.

139. Raduege, K.M.; Kleshinski, J.F.; Ryckman, J.V.; Tetzlaff, J.E. Anesthetic considerations of the herbal, kava. J. Clin. Anesth. 2004, 16, 305-311.

140. Russmann, S.; Lauterburg, B.H.; Helbling, A. Kava hepatotoxicity. Ann. Intern. Med. 2001, 135, 68-69.

141. Escher, M.; Desmeules, J.; Giostra, E.; Mentha, G. Hepatitis associated with Kava, a herbal remedy for anxiety. BMJ 2001, 322, 139.

142. Mathews, J.M.; Etheridge, A.S.; Valentine, J.L.; Black, S.R.; Coleman, D.P.; Patel, P.; So, J.; Burka, L.T. Pharmacokinetics and disposition of the kavalactone kawain: Interaction with kava extract and kavalactones in vivo and in vitro. Drug Metab. Dispos. 2005, 33, 1555-1563.

143. Bent, S.; Kane, C.; Shinohara, K.; Neuhaus, J.; Hudes, E.S.; Goldberg, H.; Avins, A.L. Saw palmetto for benign prostatic hyperplasia. N. Engl. J. Med. 2006, 354, 557-566.

144. Geavlete, P.; Multescu, R.; Geavlete, B. Serenoa repens extract in the treatment of benign prostatic hyperplasia. Ther. Adv. Urol. 2011, 3, 193-198.

145. Oki, T.; Suzuki, M.; Nishioka, Y.; Yasuda, A.; Umegaki, K.; Yamada, S. Effects of saw palmetto extract on micturition reflex of rats and its autonomic receptor binding activity. J. Urol. 2005, $173,1395-1399$.

146. Cheema, P.; el-Mefty, O.; Jazieh, A.R. Intraoperative haemorrhage associated with the use of extract of Saw Palmetto herb: A case report and review of literature. J. Intern. Med. 2001, 250, $167-169$.

147. Villanueva, S.; Gonzalez, J. Coagulopathy induced by saw palmetto: A case report. Boletin 2009, $101,48-50$.

148. Freeman, M.P.; Fava, M.; Lake, J.; Trivedi, M.H.; Wisner, K.L.; Mischoulon, D. Complementary and alternative medicine in major depressive disorder: The American Psychiatric Association Task Force report. J. Clin. Psychiatry 2010, 71, 669-681. 
149. Karioti, A.; Bilia, A.R. Hypericins as potential leads for new therapeutics. Int. J. Mol. Sci. 2010, $11,562-594$.

150. Lawvere, S.; Mahoney, M.C. St. John's wort. Am. Fam. Physician 2005, 72, 2249-2254.

151. Zanoli, P. Role of hyperforin in the pharmacological activities of St. John's Wort. CNS Drug Rev. 2004, 10, 203-218.

152. Izzo, A.A. Drug interactions with St. John's Wort (Hypericum perforatum): A review of the clinical evidence. Int. J. Clin. Pharmacol. Ther. 2004, 42, 139-148.

153. Yoshitake, T.; Iizuka, R.; Yoshitake, S.; Weikop, P.; Muller, W.E.; Ogren, S.O.; Kehr, J. Hypericum perforatum L (St John's wort) preferentially increases extracellular dopamine levels in the rat prefrontal cortex. Br. J. Pharmacol. 2004, 142, 414-418.

154. Schellander, R.; Donnerer, J. Antidepressants: Clinically relevant drug interactions to be considered. Pharmacology 2010, 86, 203-215.

155. Ernst, E. Second thoughts about safety of St John's wort. Lancet 1999, 354, 2014-2016.

156. Pal, D.; Mitra, A.K. MDR- and CYP3A4-mediated drug-herbal interactions. Life Sci. 2006, 78, 2131-2145.

157. Piscitelli, S.C.; Burstein, A.H.; Chaitt, D.; Alfaro, R.M.; Falloon, J. Indinavir concentrations and St John's wort. Lancet 2000, 355, 547-548.

158. Yue, Q.Y.; Bergquist, C.; Gerden, B. Safety of St John's wort (Hypericum perforatum). Lancet 2000, 355, 576-577.

159. Ruschitzka, F.; Meier, P.J.; Turina, M.; Luscher, T.F.; Noll, G. Acute heart transplant rejection due to Saint John's wort. Lancet 2000, 355, 548-549.

160. Breidenbach, T.; Hoffmann, M.W.; Becker, T.; Schlitt, H.; Klempnauer, J. Drug interaction of St John's wort with cyclosporin. Lancet 2000, 355, 1912.

161. Dasgupta, A. Herbal supplements and therapeutic drug monitoring: Focus on digoxin immunoassays and interactions with St. John's wort. Ther. Drug Monit. 2008, 30, 212-217.

162. Hu, Z.P.; Yang, X.X.; Chen, X.; Cao, J.; Chan, E.; Duan, W.; Huang, M.; Yu, X.Q.; Wen, J.Y.; Zhou, S.F. A mechanistic study on altered pharmacokinetics of irinotecan by St. John's wort. Curr. Drug Metab. 2007, 8, 157-171.

163. Hall, S.D.; Wang, Z.; Huang, S.M.; Hamman, M.A.; Vasavada, N.; Adigun, A.Q.; Hilligoss, J.K.; Miller, M.; Gorski, J.C. The interaction between St John's wort and an oral contraceptive. Clin. Pharmacol. Ther. 2003, 74, 525-535.

164. Murphy, P.A.; Kern, S.E.; Stanczyk, F.Z.; Westhoff, C.L. Interaction of St. John's Wort with oral contraceptives: Effects on the pharmacokinetics of norethindrone and ethinyl estradiol, ovarian activity and breakthrough bleeding. Contraception 2005, 71, 402-408.

165. Crampsey, D.P.; Douglas, C.M.; Cooke, L.D. Nasal insertion of St John's wort: An unusual cause of epistaxis. J. Laryngol. Otol. 2007, 121, 279-280.

166. Wurglics, M.; Schubert-Zsilavecz, M. Hypericum perforatum: A “modern" herbal antidepressant: Pharmacokinetics of active ingredients. Clin. Pharmacokinet. 2006, 45, 449-468.

167. Salter, S.; Brownie, S. Treating primary insomnia-The efficacy of valerian and hops. Aust. Fam. Physician 2010, 39, 433-437. 
168. Ortiz, J.G.; Rassi, N.; Maldonado, P.M.; Gonzalez-Cabrera, S.; Ramos, I. Commercial valerian interactions with $[3 \mathrm{H}]$ Flunitrazepam and $[3 \mathrm{H}] \mathrm{MK}-801$ binding to rat synaptic membranes. Phytother. Res. 2006, 20, 794-798.

169. Wheatley, D. Medicinal plants for insomnia: A review of their pharmacology, efficacy and tolerability. J. Psychopharmacol. 2005, 19, 414-421.

170. Yuan, C.S.; Mehendale, S.; Xiao, Y.; Aung, H.H.; Xie, J.T.; Ang-Lee, M.K. The gammaaminobutyric acidergic effects of valerian and valerenic acid on rat brainstem neuronal activity. Anesth. Analg. 2004, 98, 353-358, table of contents.

171. Leuschner, J.; Muller, J.; Rudmann, M. Characterisation of the central nervous depressant activity of a commercially available valerian root extract. Arzneim. Forsch. 1993, 43, 638-641.

172. Gooneratne, N.S. Complementary and alternative medicine for sleep disturbances in older adults. Clin. Geriatr. Med. 2008, 24, 121-138, viii.

173. Taavoni, S.; Ekbatani, N.; Kashaniyan, M.; Haghani, H. Effect of valerian on sleep quality in postmenopausal women: A randomized placebo-controlled clinical trial. Menopause 2011, 18, 951-955.

174. Taibi, D.M.; Landis, C.A.; Petry, H.; Vitiello, M.V. A systematic review of valerian as a sleep aid: Safe but not effective. Sleep Med. Rev. 2007, 11, 209-230.

175. Garges, H.P.; Varia, I.; Doraiswamy, P.M. Cardiac complications and delirium associated with valerian root withdrawal. JAMA 1998, 280, 1566-1567.

176. Anderson, G.D.; Elmer, G.W.; Kantor, E.D.; Templeton, I.E.; Vitiello, M.V. Pharmacokinetics of valerenic acid after administration of valerian in healthy subjects. Phytother. Res. 2005, 19, 801-803.

177. Anderson, G.D.; Elmer, G.W.; Taibi, D.M.; Vitiello, M.V.; Kantor, E.; Kalhorn, T.F.; Howald, W.N.; Barsness, S.; Landis, C.A. Pharmacokinetics of valerenic acid after single and multiple doses of valerian in older women. Phytother. Res. 2010, 24, 1442-1446.

178. Cohen, D.L.; del Toro, Y. A case of valerian-associated hepatotoxicity. J. Clin. Gastroenterol. 2008, 42, 961-962.

179. Basila, D.; Yuan, C.S. Effects of dietary supplements on coagulation and platelet function. Thromb. Res. 2005, 117, 49-53; discussion 65-47.

180. Ling, S.; Dai, A.; Guo, Z.; Yan, X.; Komesaroff, P.A. Effects of a Chinese herbal preparation on vascular cells in culture: Mechanisms of cardiovascular protection. Clin. Exp. Pharm. Physiol. 2005, 32, 571-578.

181. Gao, Z.Y.; Xu, H.; Shi, D.Z.; Wen, C.; Liu, B.Y. Analysis on outcome of 5284 patients with coronary artery disease: The role of integrative medicine. J. Ethnopharmacol. 2012, 141, $578-583$.

182. Zhang, H.C.; Liu, W.; Yuan, H.T.; Tang, Y.S. Salvia Miltiorrhiza reduces plasma levels of asymmetric ADMA in patients with non-ST elevation myocardial infarction undergoing percutaneous coronary intervention. Zhongguo Zhong Xi Yi Jie He Za Zhi 2014, 34, 1436-1439.

183. Chen, J.; Lv, Q.; Yu, M.; Zhang, X.; Gou, J. Randomized clinical trial of Chinese herbal medications to reduce wound complications after mastectomy for breast carcinoma. Br. J. Surg. 2010, 97, 1798-1804. 
184. Luo, H.W.; Hu, X.J.; Wang, N.; Ji, J. Platelet aggregation inhibitors from Salvia miltiorrhiza Bunge. Yao Xue Xue Bao 1988, 23, 830-834.

185. Maione, F.; de Feo, V.; Caiazzo, E.; de Martino, L.; Cicala, C.; Mascolo, N. Tanshinone IIA, a major component of Salvia milthorriza Bunge, inhibits platelet activation via Erk-2 signaling pathway. J. Ethnopharmacol. 2014, 155, 1236-1242.

186. Maione, F.; Cantone, V.; Chini, M.G.; de Feo, V.; Mascolo, N.; Bifulco, G. Molecular mechanism of tanshinone IIA and cryptotanshinone in platelet anti-aggregating effects: An integrated study of pharmacology and computational analysis. Fitoterapia 2015, 100, 174-178.

187. Zhou, S.; Chan, E. Effect of ubidecarenone on warfarin anticoagulation and pharmacokinetics of warfarin enantiomers in rats. Drug Metab. Drug Interact. 2001, 18, 99-122.

188. Zhou, Q.; Zhou, S.; Chan, E. Effect of coenzyme Q10 on warfarin hydroxylation in rat and human liver microsomes. Curr. Drug Metab. 2005, 6, 67-81.

189. Spigset, O. Reduced effect of warfarin caused by ubidecarenone. Lancet 1994, 344, 1372-1373.

190. Engelsen, J.; Nielsen, J.D.; Hansen, K.F. Effect of Coenzyme Q10 and Ginkgo biloba on warfarin dosage in patients on long-term warfarin treatment. A randomized, double-blind, placebocontrolled cross-over trial. Ugeskr. Laeger 2003, 165, 1868-1871.

191. Shalansky, S.; Lynd, L.; Richardson, K.; Ingaszewski, A.; Kerr, C. Risk of warfarin-related bleeding events and supratherapeutic international normalized ratios associated with complementary and alternative medicine: A longitudinal analysis. Pharmacotherapy 2007, 27, 1237-1247.

192. Evans, M.; Sharma, P.; Guthrie, N. A randomized, double-blind, crossover study on the pharmacokinetics of a novel formulation of $\mathrm{CoQ}(1)(0)$ with pyridoxal 5'-phosphate and phosphatidyl choline. J. Diet Suppl. 2010, 7, 314-324.

193. Huskisson, E.C. Glucosamine and chondroitin for osteoarthritis. J. Int. Med. Res. 2008, 36, 1161-1179.

194. Miller, K.L.; Clegg, D.O. Glucosamine and chondroitin sulfate. Rheum. Dis. Clin. North Am. 2011, 37, 103-118.

195. Clegg, D.O.; Reda, D.J.; Harris, C.L.; Klein, M.A.; O’Dell, J.R.; Hooper, M.M.; Bradley, J.D.; Bingham, C.O., 3rd; Weisman, M.H.; Jackson, C.G.; et al. Glucosamine, chondroitin sulfate, and the two in combination for painful knee osteoarthritis. N. Engl. J. Med. 2006, 354, 795-808.

196. Tang, J.; Neidigh, J.L.; Cooksey, R.C.; McClain, D.A. Transgenic mice with increased hexosamine flux specifically targeted to beta-cells exhibit hyperinsulinemia and peripheral insulin resistance. Diabetes 2000, 49, 1492-1499.

197. Scroggie, D.A.; Albright, A.; Harris, M.D. The effect of glucosamine-chondroitin supplementation on glycosylated hemoglobin levels in patients with type 2 diabetes mellitus: A placebo-controlled, double-blinded, randomized clinical trial. Arch. Intern. Med. 2003, 163, $1587-1590$.

198. Knudsen, J.F.; Sokol, G.H. Potential glucosamine-warfarin interaction resulting in increased international normalized ratio: Case report and review of the literature and MedWatch database. Pharmacotherapy 2008, 28, 540-548.

199. Setnikar, I.; Rovati, L.C. Absorption, distribution, metabolism and excretion of glucosamine sulfate. A review. Arzneim. Forsch. 2001, 51, 699-725. 
200. Persiani, S.; Rotini, R.; Trisolino, G.; Rovati, L.C.; Locatelli, M.; Paganini, D.; Antonioli, D.; Roda, A. Synovial and plasma glucosamine concentrations in osteoarthritic patients following oral crystalline glucosamine sulphate at therapeutic dose. Osteoarthr. Cartil. 2007, 15, 764-772.

201. Volpi, N. Oral absorption and bioavailability of ichthyic origin chondroitin sulfate in healthy male volunteers. Osteoarthr. Cartil. 2003, 11, 433-441.

202. Wall, R.; Ross, R.P.; Fitzgerald, G.F.; Stanton, C. Fatty acids from fish: The anti-inflammatory potential of long-chain omega-3 fatty acids. Nutr. Rev. 2010, 68, 280-289.

203. Bosch, J.; Gerstein, H.C.; Dagenais, G.R.; Diaz, R.; Dyal, L.; Jung, H.; Maggiono, A.P.; Probstfield, J.; Ramachandran, A.; Riddle, M.C.; et al. n-3 fatty acids and cardiovascular outcomes in patients with dysglycemia. N. Engl. J. Med. 2012, 367, 309-318.

204. Dyerberg, J. Platelet-Vessel wall interaction: Influence of diet. Philos. Trans. R. Soc. Lond. B Biol. Sci. 1981, 294, 373-381.

205. Lazarus, S.A.; Garg, M.L. The effects of tomato extract (TE) and omega-3 fatty acids on platelet cAMP levels and inositol triphosphate (IP(3)) release. Asia Pac. J. Clin. Nutr. 2003, 12, S20.

206. Sarris, G.E.; Fann, J.I.; Sokoloff, M.H.; Smith, D.L.; Loveday, M.; Kosek, J.C.; Stephens, R.J.; Cooper, A.D.; May, K.; Willis, A.L.; et al. Mechanisms responsible for inhibition of vein-graft arteriosclerosis by fish oil. Circulation 1989, 80, I109-1123.

207. Thorwest, M.; Balling, E.; Kristensen, S.D.; Aagaard, S.; Hakami, A.; Husted, S.E.; Marqversen, J.; Hjortdal, V.E. Dietary fish oil reduces microvascular thrombosis in a porcine experimental model. Thromb. Res. 2000, 99, 203-208.

208. Phang, M.; Sinclair, A.J.; Lincz, L.F.; Garg, M.L. Gender-specific inhibition of platelet aggregation following omega-3 fatty acid supplementation. Nutr. Metab. Cardiovasc. Dis. 2012, 22, 109-114.

209. Harris, W.S. Expert opinion: Omega-3 fatty acids and bleeding-cause for concern? Am. J. Cardiol. 2007, 99, S44-S46.

210. Salisbury, A.C.; Harris, W.S.; Amin, A.P.; Reid, K.J.; O’Keefe, J.H., Jr.; Spertus, J.A. Relation between red blood cell omega-3 fatty acid index and bleeding during acute myocardial infarction. Am. J. Cardiol. 2012, 109, 13-18.

211. Stanger, M.J.; Thompson, L.A.; Young, A.J.; Lieberman, H.R. Anticoagulant activity of select dietary supplements. Nutr. Rev. 2012, 70, 107-117.

212. Jalili, M.; Dehpour, A.R. Extremely prolonged INR associated with warfarin in combination with both trazodone and omega-3 fatty acids. Arch. Med. Res. 2007, 38, 901-904.

213. Buckley, M.S.; Goff, A.D.; Knapp, W.E. Fish oil interaction with warfarin. Ann. Pharmacother. 2004, 38, 50-52.

214. McClaskey, E.M.; Michalets, E.L. Subdural hematoma after a fall in an elderly patient taking high-dose omega-3 fatty acids with warfarin and aspirin: Case report and review of the literature. Pharmacotherapy 2007, 27, 152-160.

215. Broughton, G., 2nd; Crosby, M.A.; Coleman, J.; Rohrich, R.J. Use of herbal supplements and vitamins in plastic surgery: A practical review. Plast. Reconstr. Surg. 2007, 119, 48e-66e.

216. Mehta, J.B.; Singhal, S.B.; Mehta, B.C. Ascorbic-acid-induced haemolysis in G-6-PD deficiency. Lancet 1990, 336, 944.

217. Rosenthal, G. Interaction of ascorbic acid and warfarin. JAMA 1971, 215, 1671. 
218. Weintraub, M.; Griner, P.F. Warfarin and ascorbic acid: Lack of evidence for a drug interaction. Toxicol. Appl. Pharmacol. 1974, 28, 53-56.

219. Feetam, C.L.; Leach, R.H.; Meynell, M.J. Lack of a clinically important interaction between warfarin and ascorbic acid. Toxicol. Appl. Pharmacol. 1975, 31, 544-547.

220. Food and Nutrition Board; Institute of Medicine, Dietary Reference Intakes for Vitamin C, Vitamin E, Selenium, and Carotenoids; National Academy Press: Washington, DC, USA, 2000.

221. Shuster, L.T.; Thielen, J., Evidence-based use of vitamin supplements. In Textbook of Complementary and Alternative Medicine, 2nd ed.; Yuan, C.S., Bieber, E.J., Bauer, B.A., Eds.; Informa Healthcare: Abingdon, UK, 2006; pp. 99-108.

222. Cox, A.C.; Rao, G.H.; Gerrard, J.M.; White, J.G. The influence of vitamin E quinone on platelet structure, function, and biochemistry. Blood 1980, 55, 907-914.

223. Szuwart, T.; Brzoska, T.; Luger, T.A.; Filler, T.; Peuker, E.; Dierichs, R. Vitamin E reduces platelet adhesion to human endothelial cells in vitro. Am. J. Hematol. 2000, 65, 1-4.

224. Corrigan, J.J., Jr.; Ulfers, L.L. Effect of vitamin E on prothrombin levels in warfarin-induced vitamin K deficiency. Am. J. Clin. Nutr. 1981, 34, 1701-1705.

225. Kim, J.M.; White, R.H. Effect of vitamin E on the anticoagulant response to warfarin. Am. J. Cardiol. 1996, 77, 545-546.

226. Booth, S.L.; Golly, I.; Sacheck, J.M.; Roubenoff, R.; Dallal, G.E.; Hamada, K.; Blumberg, J.B. Effect of vitamin E supplementation on vitamin $\mathrm{K}$ status in adults with normal coagulation status. Am. J. Clin. Nutr. 2004, 80, 143-148.

227. Steiner, M.; Glantz, M.; Lekos, A. Vitamin E plus aspirin compared with aspirin alone in patients with transient ischemic attacks. Am. J. Clin. Nutr. 1995, 62, 1381S-1384S.

228. Dereska, N.H.; McLemore, E.C.; Tessier, D.J.; Bash, D.S.; Brophy, C.M. Short-term, moderate dosage Vitamin E supplementation may have no effect on platelet aggregation, coagulation profile, and bleeding time in healthy individuals. J. Surg. Res. 2006, 132, 121-129.

229. Kaye, A.D.; Kucera, I.; Sabar, R. Perioperative anesthesia clinical considerations of alternative medicines. Anesthesiol. Clin. North Am. 2004, 22, 125-139.

230. Reddy, V.Y.; Sievert, H.; Halperin, J.; Doshi, S.K.; Buchbinder, M.; Neuzil, P.; Huber, K.; Whisenant, B.; Kar, S.; Swarup, V.; et al. Percutaneous left atrial appendage closure $v s$. warfarin for atrial fibrillation: A randomized clinical trial. JAMA 2014, 312, 1988-1998.

(C) 2015 by the authors; licensee MDPI, Basel, Switzerland. This article is an open access article distributed under the terms and conditions of the Creative Commons Attribution license (http://creativecommons.org/licenses/by/4.0/). 